Number of words without references $=12723$ (14684 with references)

\title{
Reviewing the Use of the Theory of Inventive Problem Solving (TRIZ) in Green Supply Chain Problems
}

\author{
Fatima Zahra Ben Moussa ${ }^{\text {a,* }}$, benmoussafatimazahra@gmail.com \\ Ivana Rasovska ${ }^{\text {b }}$, ivana.rasovska@unistra.fr \\ Sébastien Dubois c , sebastien.dubois@insa-strasbourg.fr \\ Roland De Guio ${ }^{\text {c }}$, roland.deguio@insa-strasbourg.fr \\ Rachid Benmoussa ${ }^{\text {a }}$, benmoussa.ensa@gmail.com
}

a SyLPRO /ENSA of Marrakech,Avenue Abdelkrim Khattabi, 40000, Guéliz, Marrakech - Morocco b ICUBE / University of Strasbourg, 4 street Blaise Pascal, 67081 Strasbourg - France c LGECO / INSA of Strasbourg, 24 boulevard of victory,6700 Strasbourg - France

\footnotetext{
* Corresponding Author

Fatima Zahra Ben Moussa

SyLPRO / ENSA of Marrakech, Avenue Abdelkrim Khattabi, 40000, Guéliz, Marrakech - Morocco
}

Tel: +212621060156

Email: benmoussafatimazahra@gmail.com 


\title{
Reviewing the Use of the Theory of Inventive Problem Solving (TRIZ) in Green Supply Chain Problems
}

\begin{abstract}
The purpose of the paper is to review the practice of the theory of inventive problem solving (TRIZ) in Green Supply Chain (GSC) problems and to identify new research challenges focusing on the question: "To what extent is it necessary to evolve TRIZ tools, methods and theoretical grounding for addressing GSC inventive problems?" First, a review of the past contributions of TRIZ based methods to GSC problem resolution is presented. As the result of the papers review did not provide a comprehensive understanding of the limitations and areas of potential application of TRIZ in GSC, three experiments were conducted to complete the literature review, in order to provide a more comprehensive answer to the posed question and identify research challenges. The experiments addressing GSC problems were also conducted to explore to what extent the more mature metamethods of classical TRIZ, namely ARIZ 85 A, C and the related sub-methods, can be used as in GSM problems. The examples were chosen to explore types of GSC problems that were not yet addressed with TRIZ. The experiment results highlight limitations on the use of the TRIZ in GSC inventive problems, which were not mentioned in the GSC literature. Moreover it highlights the limitation of using the more mature meta-methods of TRIZ (ARIZ 85A and ARIZ 85C) when the conflict to overcome contains more than two evaluation parameters and one action parameter. Finally, research challenges to overcome the limitations and to improve the use of TRIZ in GSC inventive problems are stated. Among them, methods for quickly establishing the existence of classical TRIZ contradictions or for informing the problem solver when no TRIZ contradictions are present in a given inventive problem in GSC should be proposed. Such methods would permit determining whether ARIZ $85 \mathrm{C}$ could be used and avoid a long and fruitless search for a system of contradictions. Find alternatives to the algorithms proposed in the past to be able to establish the generalized contradictions of inventive problems. Make evolve meta-methods ARIZ $85 \mathrm{C}$ or substitute it with methods which can address the inventive problems that cannot be treated by ARIZ 85C.
\end{abstract}

Keywords: Green Supply Chain (GSC), theory of inventive problem solving (TRIZ), Green innovation, Optimization

\section{Introduction}

Companies today must respond to various pressures such as the depletion of resources, stricter regulations, increasing demand in terms of quality and quantity of goods and services, reactivity, personalization, and reduced costs. Simultaneously, due to the increasing awareness of the need for environmental protection among the general public (Garg et al. 2014), environmental issues have become a challenging topic for organizations involved in supply chain management (SCM). Green supply chain management (GSCM) has emerged as an important organizational philosophy in the industrial world. The goal is to attain corporate profit and market share objectives by reducing environmental risks and impact while improving the ecological efficiency of organizations and their partners (Zhu et al. 2008a).

There is a wide range of practices and initiatives that can be used in green supply chains (GSCs). GSCM practices span from green purchasing to integrated life-cycle management and concern all supply chain actors such as suppliers, manufacturers and customers. The supply chain loop is then closed with reverse logistics, which tends to identify methods for management and treatment of products at the end of their life (Anoop \& Regi Kumar 2013). To address these GSC problems, researchers have developed several multi-objective optimization problem-solving approaches to find the most advantageous compromises between economic and environmental performance. Other methods and tools are used to improve the implementation of GSCM practices such as Lean manufacturing, Lean \& Green and so on to eliminate or reduce lean and green wastes. Other methods such as life cycle analysis, life cycle assessment, and other related methods are also proposed for eco design of products and processes. In addition to the optimization approaches, innovative strategies are currently employed as a key element to gain a competitive advantage in the actual market sharing and acquisition 
of new markets. Manufacturers must effectively integrate environmental concerns into their regular practices to minimize environmental impact (Diabat et al. 2013). Consequently, implementing green supply chain management (GSCM) and green innovation has become increasingly important for industries to gain and maintain this competitive advantage (Zhu et al. 2008a).

This paper focuses specifically on the "Theory of Inventive Problem Solving", which is also known by its Russian acronym, TRIZ. This theory serves as the basis for several inventive problem-solving methods and tools that rely on dialectics and systemic. The conflicting situation in GSCM among contradictory objectives such as costs, environmental consequences, and product quality can be associated with the notion of contradiction in TRIZ theory. The TRIZ refuses to make a compromise and proposes to overcome these contradictions by proposing a solution satisfying the objectives. In general, problem solving cannot be distinguished from problem formulation. A respectable formulation of a problem that, in the case of the TRIZ, means formulating a relevant contradiction, means approximating a solution. Thus, the identification and extraction of contradictions is the starting point for inventive problem solving.

For the reasons cited above, the authors consider the use of TRIZ inventive problem-solving tools and methods a means of addressing future challenges in the GSCM domain to obtain green innovation solutions. The authors hypothesize that the use of the TRIZ is possible in different areas of GSC; however, they question the degree of change to be made to tools, methods and fundamental concepts of the TRIZ to be applicable to the different inventive problems encountered in GSC. Therefore, this paper initially reviews past contributions of TRIZ-based methods to GSC problem resolution, focusing on the question, "To what extent is it necessary to evolve TRIZ tools, methods and theoretical grounding for addressing GSC inventive problems?" However, because the result of this review did not provide a comprehensive understanding of the limitation and areas of potential application of the TRIZ in GSC, three experiments complement the literature review. The experiment results highlight limitations on the use of the TRIZ in GSC inventive problems, which were not mentioned in the GSC literature. Finally, research challenges to overcome these limitations are stated.

The remainder of this paper is organized as follows. Section 2 initially provides a general background on SCM and GSCM. Then, the inventive problem-solving theory TRIZ is introduced, and the link between TRIZ contradictions and the optimization search and solution problem space is developed. The last part of the background reviews the papers relating to the application of TRIZ tools and methods in GSC and GSCM. The problems involved in the implementation of TRIZ methods and tools are discussed, but no significant research challenges could be deduced directly from the bibliographic analysis. Thus, section 3 complements the literature review to provide a more comprehensive answer to the posed question and identify research challenges. Section 4 synthesizes the results and future research directions.

\section{Background}

\subsection{GSC and GSCM}

Supply chain management is defined by the Council of Supply Chain Management (SCM) Professionals (CSCMP) (2004) as "the planning and management of all activities involved in sourcing and procurement, manufacturing processes, and all logistics management activities, including coordination and collaboration with suppliers, intermediaries, third-party service providers, and customers". GSCM has emerged as an important organizational philosophy in the industrial world that has been recognized and applied by manufacturing companies. It aims to attain corporate profit and market share objectives by reducing environmental risks and impact while improving the ecological efficiency of organizations (Zhu et al. 2008b). We adopt Srivastava's definition of GSCM (Srivastava 2007) as "integrating environmental thinking into supply-chain management, including product design, material sourcing and selection, manufacturing processes, delivery of the final product to the consumers and end-of-life management of the product after its useful life".

According to (Srivastava 2007), green supply chain management consists of a wide range of practices classified into three main domains:

- Green product and packaging design, which aims to improve ecological conditions during the design or product improvement stage

- Green operation (green process design), which explores green procurement, green production/remanufacturing, reverse logistics/waste treatment and green distribution/supply, which is split into green transportation, green storage and distribution network design

- Managerial practices that correspond to a set of strategies and practices aiming to design, coordinate, and manage the operations of the Supply Chain (SC) 
In general, environmental issues have become a challenging topic for organizations involved in supply chain management (Garg et al. 2014). Moreover, organizations use innovative strategies as a key element of actual market sharing and acquisition of new markets. According to (OECD 2005) innovation is defined as "the implementation of a new or significantly improved product (good or service) or process, a new marketing method, or a new organizational method in business practices, workplace organization or external relations". According to the same source (OECD 2009) green innovation is characterized as "the creation or implementation of new, or significantly improved, products (goods and services), processes, marketing methods, organizational structures and institutional arrangements which lead to environmental improvements compared with relevant alternatives". Green innovation is a primary goal for many organizations today to achieve environmental strategic advantages. Many companies have recently recognized the concepts of green innovation, which is another face of the environmental management concept. Green innovation, in turn, helps organizations to improve the performance of GSCM by minimizing negative environmental impact and by creating differentiation of developed products and processes among competitors (Seman et al. 2012)

When implementing environmental practices in green supply chain management, companies and manufacturers face different problems that can be characterized as conflicts between green and economic objectives. To address these problems, researchers have developed several optimization problem-solving approaches and multiobjective models from operational research. The goal of these approaches and models is to choose among the best tradeoffs while considering economic and environmental objectives. These methods were primarily developed to solve green process-design problems to eliminate or reduce wastes and environmental impacts such as emissions (Kim et al. 2006), (Talaei et al. 2016), (Huang et al. 2016), and (Zhao et al. 2016). However, all domains in green operations (according to Srivastava's classification) may be subject to use multi-objective optimization methods. In the context of the green procurement, various supplier selections' strategies were proposed (Luthra et al. 2016), (Kannan et al. 2015), (Rajesh and Ravi 2015), (Su et al. 2015), and (Govindan et al. 2013). In the design of the supply chain network and transportation, the mathematical programming based on objective function and various constraints is used (Hugo and Pistikopoulos 2005), (Pishvaee and Razmi 2012), (Babazadeh et al. 2015) and (Mirkouei et al. 2016), and the fuzzy optimization is implemented (Wan et al. 2015). The reverse logistics and closed-loop supply chains subject has been pretty well covered and reviewed (Govindan and Soleimani 2016), and more recent studies proposing mathematical models offering various tradeoffs scenarios are described (Rezapour et al. 2015) and (Yi et al. 2016).

Research on managerial practices mostly tackles the strategic view of supply chain management and studies, among other things, the relationships between supply chain stakeholders and influential enablers (Diabat et al. 2014), hypotheses about the role of governance in the supply chain (Esfahbodi et al. 2016) and the relationship between GSCM practices and environmental and financial performance (Laari et al. 2016). Moreover, a special issue of the Journal of Cleaner Production in 2015 (Govindan 2015) was dedicated to the various types of supply chain relationships, governance mechanisms and innovations that can foster effective and efficient sustainable supply chain management. None of the previously mentioned research provides links between optimization means and innovative design mean for addressing GSC challenges.

In the context of product design, proposed methods and tools are primarily intended to improve products to satisfy customer demand. Green design is focused on reducing the negative effects of products and processes (Foster et al. 2011), and most proposed methods rely on life-cycle assessment methods and environmentally conscious design. Design methods and tools based on total quality management approaches such as Taguchi experimental methods (Jamshidi et al. 2012), Quality Function Deployment (QFD) (Masui et al. 2003; Büyüközkan \& Berkol 2011; Wu \& Ho 2015; Siu et al. 2015), Design Of Experiments (DOE) (Morose et al. 2011; Coronado et al. 2015), Axiomatic Design (AD) (Kannan et al. 2015), Design For Recycling (DFR) (Masanet \& Horvath 2007; Ardente et al. 2003) and Design For Disassembly (DFD) (Soh et al. 2015; Ariffin et al. 2015) are recognized as being used in problem solving in the green product design or green production process design area of GSCM.

Optimization or search problems concerning technical systems are usually described by two types of system parameters. The problem's objectives are described with evaluation parameters, which define the evaluation solution space. In addition, the system variables concerning different system configurations are described by action parameters that define the decision problem space. Thus, any solutions can be described in both evaluation and decision space, and each point of the decision space has a corresponding point in the solution space. Figure 1 illustrates the assertion in the case of a 2-dimensional solution and decision space problem. 


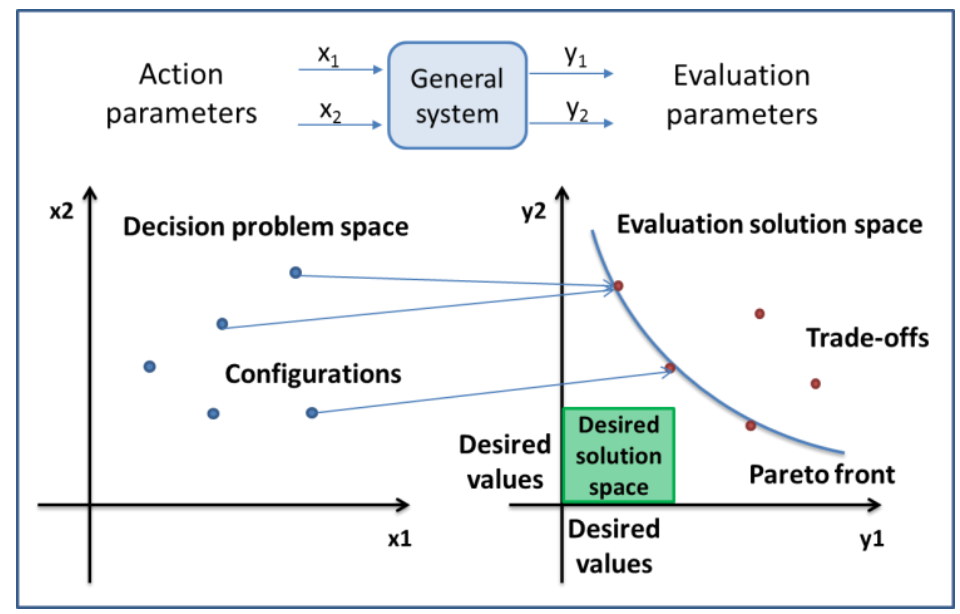

Figure 1: Illustration of search space and optimization problem

The goal is defined in the evaluation space by defining the expected range of the value of the evaluation parameters, which defines a desired solution space as a sub-space of the evaluation solution space. The purpose of the optimization methods is, for a given system model, to determine whether there are points of the decision space with corresponding points in the desired solution space. When, as in Figure 1, no correspondence exists in the desired solution space, optimization techniques can be used based on the well-known concept of Pareto dominance, on the Pareto front. The points on the Pareto front represent the best trade-offs toward the desired solution (see also Figure 1). Hence, the purpose of inventive problem-solving methods such as the TRIZ is to go beyond the limit represented by the Pareto front to prompt the evaluation parameters to arrive at a desired value by changing the system model-i.e., changing the action parameters, their interrelationships and their possible value range. Once a new model of a system is obtained, a new search or optimization problem, with the same evaluation solution space as previously used, can be stated. Problems in which no correspondence between the desired solution space and the decision space exist for the existing systems are occasionally called engineering design inventive problems.

The appearance of environmental constraints evolves the optimization problems in the GSC by adding new evaluation parameters. Consequently, the dimensions of both evaluation and desired solution spaces are increasing, and the relationship between the decision space and the solution space is changed, as is the optimization problem. Thus, new trade-offs appear, linked to the new evaluation parameters, and the new problem becomes an inventive problem.

\section{$2.2 \quad$ TRIZ}

The "Theory of Inventive Problem Solving," also known by its Russian acronym TRIZ, was developed by G. Alsthuller (Altshuller 1984) to propose a framework for the construction of methods to identify and solve problems arising during the evolution of technical systems. Initially, Alsthuller developed a set of tools and methods to encourage engineers to be more creative with the formulation and resolution of problems in the 1970s (Altshuller 1999). To improve these methods, a theoretical corpus has been developed. The TRIZ is now also a corpus of theories with foundations and assumptions that offer a framework to build problem-solving methods. However, the TRIZ is based on three axioms (grounding hypotheses):

- The laws of evolution of technical systems (referenced later as A2): in the context of the TRIZ, the evolution of technical systems has been studied, and generic trends have been formalized. The knowledge of these trends can be used with problem-solving methods for evaluating, at any given time, the maturity level of a system and its evolving trends, for orienting the problem-solving process, or for better anticipating pending problems to be solved.

- Contradictions (referenced later as A1): any evolving system should solve a number of contradictions that are the result of evolutionary trends, wishes, or opportunities for the development of the system. The concept of contradiction is based on dialectics (in the Hegelian sense), but the TRIZ model of contradictions adds a structured vision that links characters and defines contradiction to those acting on the model. This is undertaken through two levels of formulation of the contradiction: the contradiction known as a "technical contradiction," which expresses the opposition between two evaluation parameters of a system, and the "physical contradiction," which defines two states for the action parameter of the system, satisfying each of its conflicting objectives. Therefore, the generic system of the contradiction statement that is summarized in 
Figure 2 is as follows. Starting with the existing system, to obtain the desired results for evaluation parameters 1 and 2, we should simultaneously assign the action parameter the values of 1 and 2 . With the existing system, the goals of the two objectives are mutually exclusive. Note that these contradictions only exist because of the desired result, which itself results from the opportunities, wishes or constraints of the system's environment. If the contradictions are not overcome and the system does not evolve by overcoming the contradiction, the system might disappear.

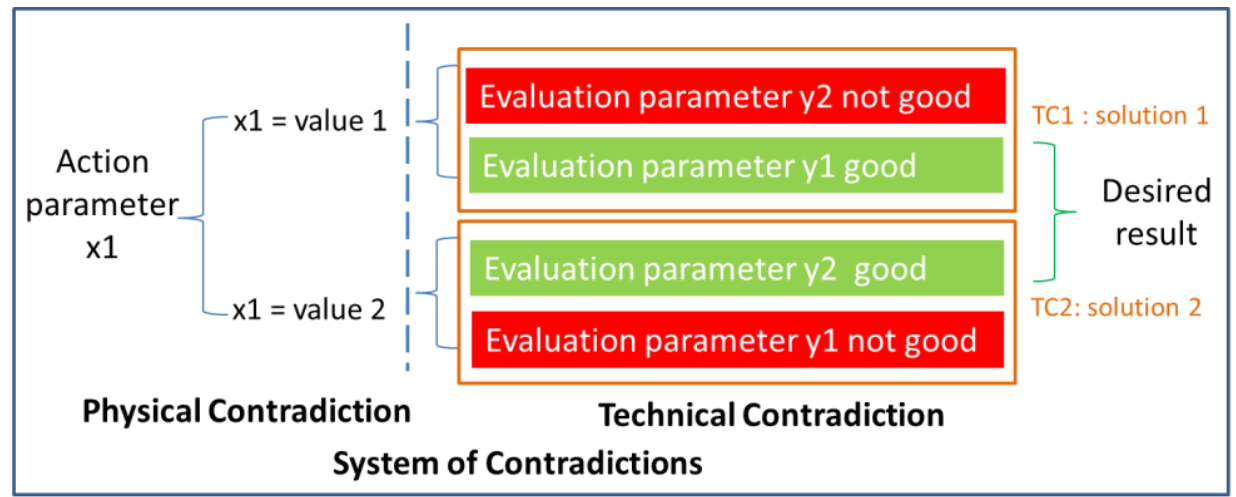

Figure 2: Classical TRIZ system of contradiction model

- The specific requirements (referenced later as A3) contextualize the evolution of the system and the problems to be solved and therefore the solutions, depending on the environmental resources with which the system evolves.

The application of the TRIZ methods depends largely on the user's experience and knowledge, but the deployment of this set of components might not be straightforward without practice and can be perceived as difficult if the problem is complex. Thus, it was necessary to provide meta-methods to guide users to combine correctly the different tools and methods for a given problem. Altshuller and his team worked for more than 25 years on the development of an algorithm to help solve problems. From the time the initial version, which was based on technical contradictions, appeared in 1961 to the last version that was developed in 1985, which uses all TRIZ methods/tools/knowledge bases, each version of ARIZ (algorithm for inventive problem solving, shown in figure 3) was tested on 1000 technical problems before being published (Khomenko et al. 2009). ARIZ is based on the step-by-step transformation of an initial problem to a stage at which it becomes easy to solve. The most recent version of ARIZ (ARIZ-85-C) contains nine key steps; each step includes many sub-steps (Chou 2014).

Note that ARIZ only addresses problem solving. Thus, to select and define a problem to solve, TRIZ offers several structural approaches in the form of a multi-screen analysis and ARIZ 85A (part 0) to represent the complexity of the evolution of a system by illustrating the contradictions within a multi-screen level of thinking between the system, its components and its super-system and the relationships among these contradictions. The selection of the contradiction to be addressed with ARIZ must be undertaken by the owner of the problem. Morerecent research proposes to organize the set of contradictions into a network of problems (Khomenko \& De Guio 2007).

The application of TRIZ is no longer restricted to technical problems. Recently, new research based on the TRIZ was conducted to extend the TRIZ approach to resolve any type of problem, i.e., not only those problems related to the evolution of technical systems (Ilevbare et al. 2013). The extension of TRIZ to solve non-technical problems has yet to be built that considers the three basic axioms of the TRIZ: the notion of a contradiction as a framework for problem formulation, the concept of a specific condition that involves the systemic view of the studied object, and the concept of the laws of evolution that state that all systems follow a set of rules, which might or might not be known depending upon the field of the studied object. Based on research concerning the generalization of the TRIZ to solve non-technical problems, some of these approaches have already been undertaken, particularly concerning the identification and formulation of problems. Today, the TRIZ has multiple recognized contributions that address various phases of problem solving, including the problem formulation phase, problem analysis phase and problem-solving phase.

There is also a link between the TRIZ model of contradiction and the correspondence model of the optimization or search problem. This link will lead us, in 2.3, to state research questions and hypotheses concerning the use of the TRIZ in GSC. To introduce this link, let us consider a 2-objective optimization problem the solutions of which are similar to those in Figure 3. The desired solution space is in green, and we are faced with an inventive 
problem because no points of the evaluation space belong to the desired solution space. More precisely, let us focus on the 2 points encircled in orange and purple, which belong to the Pareto front in the evaluation solution space. When comparing these two solutions, one can observe that solution 1 is acceptable from the point of view of evaluation parameter y1 but not y2, and vice versa for solution 2 . This conflict in the evaluation solution space is a limit of the existing system performance expressed by the so-called technical contradictions TC1 and TC2 in the TRIZ. The TRIZ theory then makes the hypothesis that the conflict between the two parameters in the evaluation space (technical contradictions in TRIZ terminology) can be depicted in the decision space by a conflict between two different values of one action parameter (physical contradiction in TRIZ terminology). Figure 3 illustrates the link between the points of the solution space and evaluation space involved in the TRIZ system of contradiction. The interesting point of the TRIZ hypothesis is that when a TRIZ system of contradiction is established, the system somehow "translates" the Pareto conflict in the decision space, which is a very interesting approach for inventive problem solving. Indeed, the model change appears primarily in the decision space (i.e., adding or removing action parameters modifying the link among action parameters); the evolution of the performances in the evaluation space is the only consequence of the model change.

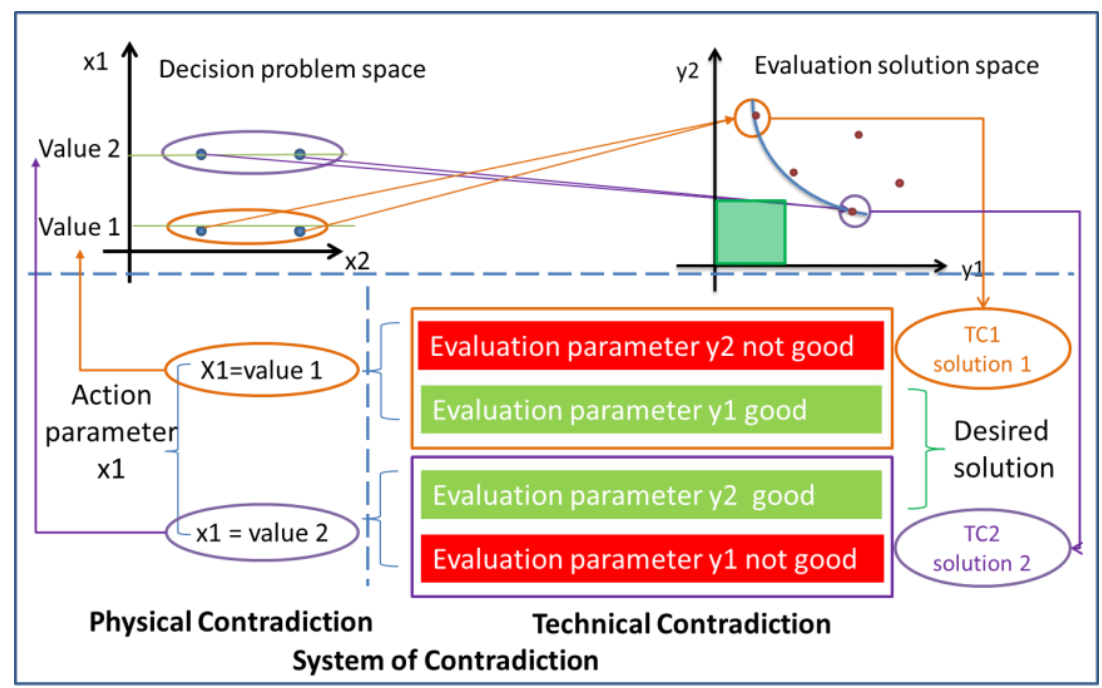

Figure 3: Link between contradictions, decision and evaluation space

Concerning classical TRIZ contradictions, there are several limitations in their definition and utilization. We note in certain situations the proven absence of contradictions appearing from the available relationships between the variables of the system, which corresponds to the contradiction definition provided by the classical TRIZ approach (Dubois et al. 2009). The observed general trend can be summarized as follows: the more experiments and knowledge concerning a system that exists, the lower the chance of finding a technical contradiction (i.e., an input for inventive problem-solving methods). Another inconvenience is that the classical technical contradiction considers only two evaluation parameters and one action parameter at the same time. The consequence is that a conflicting situation for a complex link between action parameters and performance cannot be well described. Supposing a technical contradiction exists that can be solved, nothing can be said a priori about the satisfaction of the other evaluation parameters. Moreover, an explicit definition of the context required to validate the contradictions for the solving method in the decision problem space is lacking.

To address these limitations, the concept of a generalized system of contradictions (GSC) involving generalized technical contradictions (GTC) and generalized physical contradictions (GPC) was proposed in the previous work (Dubois et al. 2011; Dubois et al. 2009) as an enhanced equivalent to the classical TRIZ contradictions. These generalized concepts avoid situations in which no classical TRIZ technical and physical contradictions exist, as was previously mentioned. The GTC model in Figure 4 replaces two evaluation parameters defined in a classical technical contradiction with two concepts of evaluation parameters. A concept consists of an evaluation parameter or a logical disjunction of several evaluation parameters. One parameter can only participate in one of the two concepts involved in a GTC. The desired result is the simultaneous satisfaction of the two concepts. In each concept, there is one or more evaluation parameters for which the solution of each generalized technical contradiction should satisfy all of the evaluation parameters associated with the two concepts. Thus, the result will be improved over the case of classical technical contradictions. Note that the classical TRIZ contradiction is a special case of generalized contradiction. Another advantage of generalized contradictions is the multiobjective character of the evaluation part, which means that the generalized technical contradiction is not limited by only two evaluation parameters; consideration of all of the evaluation parameters of the problem is suggested. 


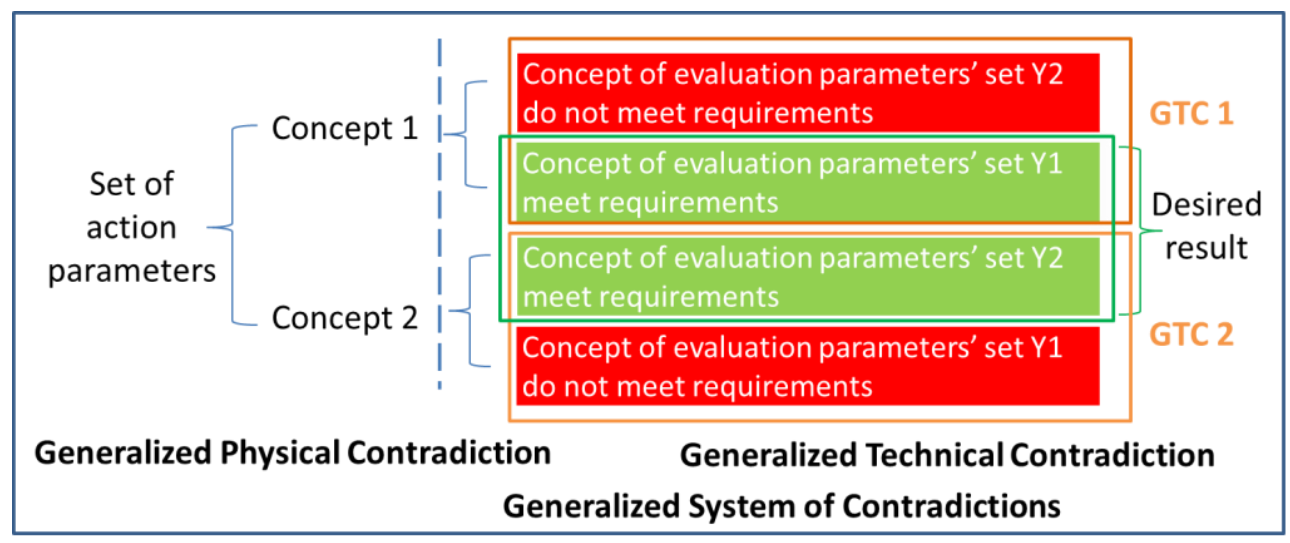

Figure 4: Generalized system of contradictions model

When considering the increasing number of evaluation parameters in GSC problems, we are faced more frequently with inventive problems, and the authors hypothesize that classical TRIZ tools might not be sufficient to describe and solve new conflicts appearing in GSC inventive problems.

\subsection{GSC innovation and TRIZ}

\subsubsection{Bibliographic sources and analysis method}

The literature review aims at exploring the past contributions of TRIZ-based methods to GSC problem resolution. The review is based on crossed research for articles published in the databases « Science Direct » and «Scopus » using following keywords: "green, environmental, supply chain, logistics, TRIZ, innovation". In total, twenty one articles addressed the application of TRIZ methods to GSC problems and were analyzed in Table 1. According to a first overview of the uses of the TRIZ in GSC problems, the existing attempts primarily focus on green product \& packaging design and green production \& remanufacturing. The application of the TRIZ in the GSC domains concerns subjects that are similar to the traditional application of TRIZ-based methods, i.e., the design of products and the design of manufacturing processes. Indeed, when considering the design of technical systems, integrating green constraints do not change the fundamental nature of product, packaging, production or remanufacturing design problems. Thus, it is not surprising that a theory and its methods, techniques and tools, which have been largely used for product and process design, can also be used for green design. However, no obvious or straightforward reason that could prevent the TRIZ from being applied to other categories of green operations domains, such as reverse logistics, waste treatment, distribution (i.e., transportation, storage, and distribution network design) or even production flow design, was provided in the literature. This observation leads one to wonder about the possibility or relevancy of using the TRIZ in these categories that are not yet covered by the TRIZ. Nevertheless, when referring to the trials of the TRIZ application in areas other than those for which it was designed, it was often necessary to adjust the tools and methods, even avoid using some of them. The authors hypothesized that the use of the TRIZ is possible in the areas of GSC mentioned above for which there is not yet feedback; however, they question the degree of change to be made to tools, methods and fundamental concepts of the TRIZ to be applicable to the different inventive problem encountered in GSC. Thus, the strategy of implementing and expanding the use of TRIZ methods raises the question, "To what extent is it necessary to evolve TRIZ tools, methods and theoretical grounding to address GSC inventive problems?" The answer to this question might also provide an opening for new research.

\subsubsection{Results of the literature analysis}

According to the analysis of the papers addressing the resolution of GSC problems with TRIZ, in response to the question posed in section 2.3.1, the authors identify three ways that applications of TRIZ can resolve problems addressed in GSC:

- Direct Application of TRIZ methods and tools without considering the three axioms of the TRIZ

- Adaptation of TRIZ methods and tools to GSC problems

- Systemic application of TRIZ methods and tools that account for the three axioms of the TRIZ 
Indeed, the direct application of some TRIZ tools and methods to green design is obvious and was established in several articles (Chen \& Chen 2007; Rau \& Fang 2009; Bashkite \& Karaulova 2012). However, these direct applications, which primarily focused on the use of the matrix for technical contradiction, have the same limits as those that can be formulated regarding the matrix, that is used in the design of technical systems when no green constraints are considered. The matrix is a statistical analysis of the most commonly used inventive principles of each type of technical contradiction in the technical systems design. The matrix only provides general answers that do not provide explicit answers at the action parameters level. Moreover, if using the approach without considering the laws of technical systems' evolution and ideality, only one out of three postulates is considered. That limitation is why, in the context of TRIZ research, and more specifically in the ARIZ approach, the use of the matrix has been replaced by other tools (physical contradiction, inventive standards) that fit the application of the 3 axioms of TRIZ.

Concerning the papers addressing the adaptation of TRIZ methods or tools to GSC domains, one can find authors who propose to rebuild a matrix or its equivalent to apply it to GSC problems. In (Srinivasan \& Kraslawski 2006), the authors propose construction of a specific matrix to design inherently safer chemical processes in which the specific contradictions of the domain are elicited and associated with TRIZ inventive principles. A similar approach can be observed in (Liu \& Chen 2001) in which the seven eco-friendly elements developed by the World Business Council for Sustainable Development (WBCSD) for green product design were formulated and linked to the inventive principles to construct a new table of inventive principles. One limitation concerning this type of "intuitive parallel" is that the inventive principles, in the context of the TRIZ, have been formulated as a generalization of solutions that have been applied and recognized as inventive from the design of a large set of past technical systems. If a parallel must be built and if the equivalent of the inventive principles must be proposed for the GSC or any technical domain, the solutions applied and recognized as inventive must be listed, analyzed and then generalized, which seems not to be performed. No information was found about the level of generality or about the method of how the new matrix was obtained.

Moreover, the use of the matrix from an experimental perspective has shown limits in its application. The fitting of the technical contradiction parameters with those of the matrix, as initially formulated by the problem solvers, is not obvious. It seems more interesting not to limit the application of TRIZ-based methods and tools to technical contradictions and the matrix.

From our point of view, if we were willing to apply the TRIZ tools and methods directly, it would be more robust to apply systemically the generic tools and methods, which have been developed to solve more than technical problems. Such research has been directed toward OTSM-TRIZ (Sokol et al. 2008). In (Fresner et al. 2010), the authors proposed a method to solve problems in Cleaner Production based on TRIZ methods. They conducted a comparison of technical system evolution and evolution strategies in Cleaner Production to adjust the goal, formulate the Ideal Final Result to state the problem, and create a functional model and analysis to find potential resources to solve the formulated problem. In (Yang \& Chen 2012; Yang \& Chen 2011), two different methods for green product design are proposed. The first is based on the application of inventive principles with evolution patterns and the principle of Ideality to help designers focus on concepts that minimize energy requirements and the complexity of engineering products. The second one is based on the evolution patterns of the TRIZ to develop innovative approaches to solve design problems. In (Kubota \& da Rosa 2013), an effective method was proposed for improving the environmental efficiency of a dairy production process by using the principle of ideality (IFR) to solve problems related to cleaner production and provide sustainable, innovative and attractive cleaner product solutions for the dairy industry. In (Russo et al. 2011), a step-by-step procedure based on the application of the Laws of evolution, substance field resources, ideality and the technical contradictions was proposed to solve problems related to green product design. Finally, the last example of this application of the TRIZ can be found in (Chou 2014) in which the authors developed an ARIZ-based method for performing the so called "improvement stage" of the Life cycle engineering (LCE) model to implement the ecodesigns of products.

\subsubsection{Discussion of the literature analysis}

The synthesis of the literature analysis is presented in Table 1, where the analyzed papers are listed and commented in regard of: the GSC domain of application of the paper, the used TRIZ methods and tools referred in the paper, the non TRIZ methods or tools that are also referred in the paper, and the direct application or the adaptation of TRIZ tools, and also the consideration of the three main axioms. For the axioms, they are referred as A1 for the laws of technical systems evolution, A2 for the formulation of problems as contradictions (technical or physical), and A3 for the consideration of specific conditions during the resolution. For A3, as it is difficult to evaluate how the problem was stated and how the specific conditions have been considered, the authors considered this point as the formulation or not of the Ideal Final Result. In TRIZ, this Ideal Final Result 
means solving the problem without introducing new resources, and searching for configurations of the system where the desired result is achieved by itself. 


\begin{tabular}{|c|c|c|c|c|}
\hline Reference & GSC domain & TRIZ tool & Coupled with other methods & $\begin{array}{l}\text { Adaptation or not of TRIZ tools } \\
\text { Consideration of TRIZ axioms }\end{array}$ \\
\hline $\begin{array}{l}\text { (Strasser \& Wimmer } \\
\text { 2003) }\end{array}$ & $\begin{array}{l}\text { Eco innovation, eco design for } \\
\text { product development }\end{array}$ & $\begin{array}{l}\text { Contradiction }+ \text { contradiction matrix }= \\
\text { categorization } \\
\text { Inventive principles = environmental } \\
\text { strategies } \\
\text { Innovation situation questionnaire }\end{array}$ & Environmental strategies & $\begin{array}{l}\text { Step by step procedure using } \\
\text { TRIZ tools } \\
\text { A1 }\end{array}$ \\
\hline (Liu \& Chen 2001) & $\begin{array}{l}\text { Product green innovative design } \\
\text { method }\end{array}$ & $\begin{array}{l}\text { Engineering parameters coupled with eco- } \\
\text { efficiency } \\
\text { Inventive principles }\end{array}$ & $\begin{array}{l}7 \text { elements of eco-efficiency by } \\
\text { WBCSD }\end{array}$ & $\begin{array}{l}\text { No contradiction information } \\
\text { considered }\end{array}$ \\
\hline (Chen \& Chen 2007) & $\begin{array}{l}\text { Active disassembly at the end- } \\
\text { of-life stage of product } \\
\text { (fasteners at the end-of-life } \\
\text { product - shape memory } \\
\text { plastics) }\end{array}$ & $\begin{array}{l}\text { Engineering parameters - contradiction } \\
\text { matrix version } 2003 \\
\text { Inventive principles } \\
\text { SU-field model }\end{array}$ & $\begin{array}{l}7 \text { elements of eco-efficiency } \\
\text { LCA or other eco design tool for } \\
\text { environmental impact loads } \\
\text { Identify the required improving } \\
\text { elements of eco-efficiency }\end{array}$ & $\begin{array}{l}\text { No verification of real existence } \\
\text { of contradiction }\end{array}$ \\
\hline (Yang \& Chen 2011) & $\begin{array}{l}\text { Preliminary eco-innovative } \\
\text { design for products }\end{array}$ & $\begin{array}{l}\text { Ideality, Inventive principles } \\
\text { Evolution patterns = green evolution rules }\end{array}$ & $\begin{array}{l}\text { Case-based reasoning for } \\
\text { accelerating eco-innovation }\end{array}$ & $\begin{array}{l}\text { No verification of contradiction } \\
\text { existence; } A 1, A 2, A 3\end{array}$ \\
\hline (Yang \& Chen 2012) & $\begin{array}{l}\text { Forecasting design of eco } \\
\text { products }\end{array}$ & Evolution patterns $=$ green evolution rules & $\begin{array}{l}\text { Case-based reasoning } \\
\text { LCA methods }\end{array}$ & $\begin{array}{l}\text { Adaptation of TRIZ } \\
\text { A2, A3 }\end{array}$ \\
\hline $\begin{array}{l}\text { (Srinivasan \& } \\
\text { Kraslawski 2006) }\end{array}$ & Design of chemical processes & $\begin{array}{l}\text { Characteristics = parameters } \\
\text { Inventive principles } \\
\text { Contradiction between characteristics solved } \\
\text { with the aid of contradiction matrix }\end{array}$ & $\begin{array}{l}\text { Opportunities of coupling with } \\
\text { methods used in chemical processes }\end{array}$ & $\begin{array}{l}\text { Adaptation of TRIZ } \\
\text { A1 }\end{array}$ \\
\hline (Rau \& Fang 2009) & $\begin{array}{l}\text { Product package design for } \\
\text { logistics }\end{array}$ & $\begin{array}{l}\text { Contradiction matrix for conflicts between } \\
\text { fuzzy attributes (parameters) } \\
\text { Inventive principles }\end{array}$ & QFD, Fuzzy theory & $\begin{array}{l}\text { Statistical use of matrix, do not } \\
\text { respect the basic axioms } \\
\text { A1 }\end{array}$ \\
\hline (Fresner et al. 2010) & $\begin{array}{l}\text { Generating process } \\
\text { improvement options }\end{array}$ & $\begin{array}{l}\text { Laws of evolution in correspondence to CP } \\
\text { strategies } \\
\text { Ideal final result gives optimization strategy } \\
\text { Speaks about functional analysis, ARIZ }\end{array}$ & Strategies of cleaner production & $\begin{array}{l}\text { Suggested when limited } \\
\text { professional experience } \\
\text { A2, A3 }\end{array}$ \\
\hline $\begin{array}{l}\text { (D’Anna \& Cascini } \\
\text { 2011) }\end{array}$ & $\begin{array}{l}\text { Preliminary analysis for } \\
\text { sustainable systems }\end{array}$ & $\begin{array}{l}\text { Laws of evolution } \\
\text { System operator }\end{array}$ & Sustainability map & $\begin{array}{l}\text { Adaptation of TRIZ tools } \\
\mathrm{A} 1, \mathrm{~A} 2, \mathrm{~A} 3\end{array}$ \\
\hline (Chulvi \& Vidal 2011) & Eco design of product & Evolution trends $=7$ LiDS principles & $\begin{array}{l}\text { Eco-design strategy wheel LiDS ( } 7 \\
\text { principles) }\end{array}$ & $\begin{array}{l}\text { One of three basic axiom used, } \\
\text { remake of solution principles by } \\
\text { creating database; A2 }\end{array}$ \\
\hline $\begin{array}{l}\text { (Kubota \& da Rosa } \\
\text { 2013) }\end{array}$ & $\begin{array}{l}\text { Identification and conception of } \\
\mathrm{CP} \text { opportunities }\end{array}$ & $\begin{array}{l}\text { IFR } \\
\text { Resources } \\
\text { Functional analysis }\end{array}$ & $\begin{array}{l}\text { Developed methodology: } \\
\text { functional analysis, trimming, IFR, } \\
\text { resources, inventive solutions }\end{array}$ & $\begin{array}{l}\text { Adaptation of TRIZ tools in } \\
\text { developed methodology; A3 }\end{array}$ \\
\hline
\end{tabular}




\begin{tabular}{|c|c|c|c|c|}
\hline Reference & GSC domain & TRIZ tool & Coupled with other methods & $\begin{array}{l}\text { Adaptation or not of TRIZ tools } \\
\text { Consideration of TRIZ axioms }\end{array}$ \\
\hline $\begin{array}{l}\text { (Bashkite \& Karaulova } \\
\text { 2012) }\end{array}$ & $\begin{array}{l}\text { Green thinking in Lean } \\
\text { fundamentals }\end{array}$ & $\begin{array}{l}\text { Parameters = wastes } \\
\text { Contradiction in lean \& green wastes } \\
\text { Contradiction matrix, Suggestion of ARIZ }\end{array}$ & Lean \& Green wastes & $\begin{array}{l}\text { Engineering parameters =wastes } \\
\text { (in each waste contradiction); A1 }\end{array}$ \\
\hline (Russo et al. 2011) & Eco design methods & $\begin{array}{l}\text { Ideality, Resources } \\
\text { Laws of technical evolution }\end{array}$ & $\begin{array}{l}\text { Guidelines for eco-design of } \\
\text { product linking eco-assessment } \\
\text { methods and eco-innovation } \\
\text { methods }\end{array}$ & $\begin{array}{l}\text { Reorganization of TRIZ tools } \\
\text { A1, A2, A3 }\end{array}$ \\
\hline (Russo et al. 2014) & $\begin{array}{l}\text { Design of new greener products } \\
\text { by guidelines }\end{array}$ & $\begin{array}{l}\text { Inventive principles, resources, standards, } \\
\text { trends }\end{array}$ & $\begin{array}{l}\text { Proposed method iTree integrating } \\
\text { different tools (LCA, FMEA, ..) } \\
\text { with TRIZ tools }\end{array}$ & $\begin{array}{l}\text { Coupling TRIZ tools with eco- } \\
\text { design methods, Matrix linking } \\
\text { objectives and tools/methods, } \\
\text { Redefinition of standards }\end{array}$ \\
\hline $\begin{array}{l}\text { (Russo \& Serafini } \\
\text { 2015) }\end{array}$ & $\begin{array}{l}\text { New way of thinking eco } \\
\text { improvement, not optimization } \\
\text { but starting from contradiction }\end{array}$ & $\begin{array}{l}\text { Predefined technical contradictions } \\
\text { Look for physical contradiction and } 2 \text { nd } \\
\text { evaluation parameter }\end{array}$ & $\begin{array}{l}\text { Integrate contradiction prompter in } \\
\text { life cycle assessment }\end{array}$ & $\begin{array}{l}\text { Contradictions obtained by } \\
\text { experts - predefined but not } \\
\text { checked if really exist, A1 }\end{array}$ \\
\hline (Chou 2014) & $\begin{array}{l}\text { Search of improvement } \\
\text { opportunities in eco design of } \\
\text { products }\end{array}$ & Couple LCE with ARIZ & Life cycle engineering model & $\begin{array}{l}\text { Application of ARIZ in eco- } \\
\text { design in specific domain, A1, A3 }\end{array}$ \\
\hline (Zhang et al. 2014) & $\begin{array}{l}\text { Ergonomic product innovative } \\
\text { design }\end{array}$ & $\begin{array}{l}\text { Specific and generic contradiction } \\
\text { Contradiction matrix } \\
\text { Inventive principles, Separation principles }\end{array}$ & $\begin{array}{l}\text { Customer satisfaction needs, House } \\
\text { of quality, Quality Function } \\
\text { Deployment, Fuzzy group decision- } \\
\text { making theory }\end{array}$ & $\begin{array}{l}\text { Lacks in TRIZ: no method for key } \\
\text { problems, need of designers' } \\
\text { knowledge, no method for } \\
\text { alternative evaluation, A1 }\end{array}$ \\
\hline (Thurnes et al. 2014) & $\begin{array}{l}\text { Waste elimination in Lean } \\
\text { production- Environment }\end{array}$ & Physical contradiction & Necessary waste & $\begin{array}{l}\text { Necessary waste }=\text { contradictions } \\
\text { A1 }\end{array}$ \\
\hline (Abramov et al. 2015) & $\begin{array}{l}\text { Accelerating innovation in } \\
\text { chemical processes }\end{array}$ & $\begin{array}{l}\text { TRIZ innovation roadmap } \\
\text { Speak about ARIZ, contradiction matrix, } \\
\text { inventive principles, FOS }\end{array}$ & $\begin{array}{l}\text { Stage-gate process, FMEA } \\
\text { Flow Analysis, Cause Effect Chains } \\
\text { Analysis }\end{array}$ & $\begin{array}{l}\text { Propose overview of TRIZ tools } \\
\text { useful in innovation in chemical } \\
\text { processes, A1 }\end{array}$ \\
\hline (Vidal et al. 2015) & $\begin{array}{l}\text { Eco-innovation of ceramic } \\
\text { industry products }\end{array}$ & Laws of evolution & $\begin{array}{l}\text { Fuzzy cognitive map, eco design } \\
\text { strategy wheel, evolution of eco } \\
\text { design }\end{array}$ & $\begin{array}{l}\text { Laws of evolution linked to } \\
\text { evolution of eco design to make } \\
\text { forecasting } \\
\text { A2 }\end{array}$ \\
\hline (Zhou \& Zhao 2016) & $\begin{array}{l}\text { Options for reducing carbon } \\
\text { emissions (alternative CP } \\
\text { measures) }\end{array}$ & Ideality Evolution trends and evolution lines & $\begin{array}{l}\text { IPAT equation (environ. impact, } \\
\text { population, affluence and } \\
\text { technology)=variables } \\
\text { Strategies of cleaner production }\end{array}$ & $\begin{array}{l}\text { Do not precise tools, cites other } \\
\text { authors } \\
\text { A2 }\end{array}$ \\
\hline
\end{tabular}

Table 1: Analysis of reviewed GSC papers using TRIZ 
Based on an analysis of papers addressing the TRIZ in the GSC problems, TRIZ can be used for building problem-solving methods to address GSCM problems. Moreover, the authors are curious, on the one hand, about which tools and methods in the TRIZ corpus should be used, and on the other hand, about the interest or relevance of building methods devoted to GSC that apply TRIZ-based methods. Practices shown in the literature lead us to believe that most practical studies did not use TRIZ methods and tools according to its theory. However, the TRIZ has not been exploited in some articles as advocated by Altshuller; TRIZ tools and methods seem to be used outside of the general framework in which these tools were created. For instance, the effective use of the TRIZ requires the consideration of three basic axioms when solving a problem. Note that the basic axioms have not been considered in all papers and in frequent uses of some TRIZ methods and tools, such as the technical contradictions and the TRIZ matrix. As stated previously, the use of such a matrix, regardless of the laws of evolution, leads to practices that are not in accordance with TRIZ postulates. According to the TRIZ, clearly stating the core of the problem, working on its resolution, seeking ideal solutions and considering the laws of technical systems evolution is required for the systemic application of TRIZ methods and tools. Nevertheless, results were obtained even when not using the most sophisticated method. The same type of result is seen in the application of the TRIZ in engineering design, in which it is also observed that when problems become more difficult and cannot be solved with this approach, the user gives up and no longer uses the betterevaluated TRIZ methods because they require significantly more time to learn.

\section{$2.4 \quad$ Research gaps}

To summarize, the literature analysis confirms that TRIZ tools can be used in some GSC problems with or without adaptation. However, it is surprising that only one paper reported an effective use of ARIZ 85C, the more mature meta-method proposed by Altshuller. Indeed, the ARIZ profits from all TRIZ hypotheses and from an understanding of the physical contradictions. The authors of this paper wonder whether ARIZ 85C and ARIZ $85 \mathrm{~A}$ can be used without change in GSC inventive problems. Note that the concept of system of contradiction was not mentioned in the reported literature about GSC. Is this point due to reasons intrinsic to GSC inventive problems? The purpose of the next section 0 is to answer these questions.

The following experiments originate from two main motivations: exploring the use of the TRIZ for types of GSC problems that have not yet been explored, and understanding whether the more mature meta-method of the TRIZ could be used for addressing them. Some authors of this paper have sufficient experience with TRIZ applications and development. Therefore, it was decided that experimental situations would be built that applied ARIZ 85A and ARIZ 85C and the more recent TRIZ-based method for identifying contradiction from experiments (Lin et al., 2013) and (Lin et al. 2015) to typical problems occurring in a standard and simple supply system in which feedback that would answer our questions is retained.

One can consider that only 3 articles take into account the 3 mains axioms of TRIZ, but that these articles are tackling problems about design of technical systems, for which the TRIZ based methods and tools have been specifically developed.

\section{Completing the review with experiments}

\subsection{Introducing the experiments}

The first experimental situation is based on an inventory management problem in a pharmaceutical product manufacturing company. To understand, analyze, and solve the problem, two classic and mature meta-methods proposed by G. Altshuller were used, namely ARIZ 85A for analyzing the initial situation and stating the system of contradiction to be solved, and ARIZ 85C for providing a new concept of a system overcoming the contradiction. In addition, the discrete event simulation Witness was used for comparing the performances of the initial and the new system. After the problem solving, we researched the extent to which the problem and solutions that were proposed could be described with elementary TRIZ components and models, such as the matrix linking the generic conflicting parameters to the 40 inventive principles for overcoming a technical contradiction. This research was conducted to experiment with the difficulty of using these principles without the adjustments that were proposed in the paper (Chen \& Chen 2007) and to offer our feedback on the existing proposed customization for GSCM (Srinivasan \& Kraslawski 2006).

The second experimental situation addresses the same problem as in the first experiment, but the solving process uses the computerized method proposed in (Lin et al. 2013) and (Lin et al. 2015) rather than ARIZ 85A to state the contradictions to be solved. It is the first time this methodology has been applied to an SC problem. 
The third experiment addresses a GSC problem that highlights some limitations of classical TRIZ groundings and tools when addressing multi-objective GSC inventive problems. These limitations are not provided in the papers from the GSC literature reviewed in section 2.3.

The problems were treated by a scaled-down problem-solving team composed of four members: two volunteers, who applied the chosen meta-methods, an expert in TRIZ, and the owner of the problem. All related information is presented in the next sections.

\subsection{First experiment}

\subsubsection{Initial problem statement}

The quality service of a pharmaceutical product manufacturing company experiences a significant growth in its activities. This service tests the quality of the products as they are produced. As the production evolves, the quality activity also evolves. To perform the experiments, the quality service uses products (reagents and consumables) that have expiration dates. The service observed a significant loss in purchased products because its inventory management did not allow the right product to be found, and purchases were not made optimally. The increase in demand has made this type of management inefficient and costly because the person who manages the stock no longer has sufficient monitoring, inventory verification or expiry date verification. After a $5 \mathrm{~S}$ project, inventory levels can be measured and an inventory management system for procurement can be implemented. For each item, the user implements a reorder point method supported by a one-card Kanban system. This Kanban card system's working principle is as follows: The Kanban card provides the reorder quantity and reorder point level. The items inventory is split into two groups. For the first group of items, the amount is equal to the reorder point level, and the second group contains the remaining items of the inventory. The first group includes the Kanban card. Parts of the second group are removed, and when the first part of the group containing the Kanban card is removed from the stock, the Kanban card is sent to make a purchase order. The Kanban card then comes back to the stock area with the provider's delivery. The two groups of items are replenished so that items are consumed FIFO—ready to repeat the cycle.

The implemented Kanban system works well. The forecasts indicate a doubling of demand for the next year on some products and an increase in the variety of analyses. Consequently, the Kanban card system must be reparameterized. The person who manages the stock proposes to double the storage space. However, the company has a problem because it lacks the space to double the amount of stock space. Making investments to create extra storage space for this type of item is an additional cost that cannot be supported by the company. Are there other solutions that satisfy the constraints of the problem at a lower cost? Several typical solutions from the SC field can be used to address this problem. Nevertheless, we decided to test the problem-solving methodology, as described in the next section.

\subsubsection{Selected problem-solving methodology}

To provide information to answer the questions posed in this paper, or at least solidify the authors' answers to these questions, we designed an experiment using the two classic and most mature TRIZ meta-methods proposed by G. Altshuller, with ARIZ 85A to analyze the situation and formulate the problem in a classical TRIZ system of contradictions format. The framework of ARIZ 85A is provided in Figure 5. The 3 first parts (from the problem analysis till the formulation of the Ideal Final Result and Physical Contradiction) of ARIZ 85C, the process of which is provided in Figure 6, was then used to resolve the issue and provide conceptual solutions to the problem. By using these methods - which are not clearly evaluated in the research on GSC - we wanted to evaluate the extent to which they could be used, the difficulty experienced by users who are not TRIZ experts, and the components that eventually needed to be changed to use them in a framework for SCM problems, including GSCM. There are two other points that must be highlighted concerning how these methods were applied. Only some parts of the method were applied or tested, only those enabling the formulation of a system of contradictions, and its resolution. Moreover, this problem could be addressed by professionals in the SC; so we did not perform a study that tested all existing solutions to understand the extent to which they offer solutions to our problem. One reasons for this choice was to evaluate the extent to which the tested methodology would lead to existing solutions, reinvent existing solutions or create new solutions (or at least not standard solutions). Another point, during the ARIZ 85C process, only the more generic tools, i.e. that were judged by the authors as being sufficiently generic to be used without major changes in many areas, were used. For example, the Inventive standards were not used in Steps 1 to 3 for the methods described in Figure 6. The analysis, without the use of inventive standards, was sufficient for providing a solution, and moreover, the Inventive Standards have been specifically developed to model technical systems' problems, and are not directly applicable to model processes' problems. 
0.1 . Determine the final goal of a solution.

0.2. Investigate a "bypass approach".

0.3. Determine which problem, the original or the bypass, makes the most sense to solve.

0.4 . Determine the required quantitative characteristics.

0.5 . Increase the required quantitative characteristics by considering the time of invention implementation.

0.6. Define the requirements for the specific conditions in which the invention is going to function.

0.7. Examine if it is possible to solve the problem by direct application of the Inventive Standards.

0.8 . Define the problem more precisely utilizing patent information.

0.9. Use STC (Size, Time, Cost) operator.

Figure 5: Nine main steps to analyze the initial situation (ARIZ 85A) (Altshuller 1985)

To validate the concept of solution obtained when applying ARIZ 85C, a model of the initial and new solutions is implemented on the discrete event simulator (Witness), and a set of experiments is performed to provide a sample of the mapping between the action parameters and the performance parameters (stock breakdown and stock value). The Experimenter of Witness allows performing mono-objective optimization (i.e., the sequence of action parameters can be managed due to a simulated annealing program). The Experimenter also allows conducting design of experiments. We did use these two functions of Witness to define the Pareto front of both the initial and new solutions. Thus, we could compare their performance by comparing their Pareto front. 


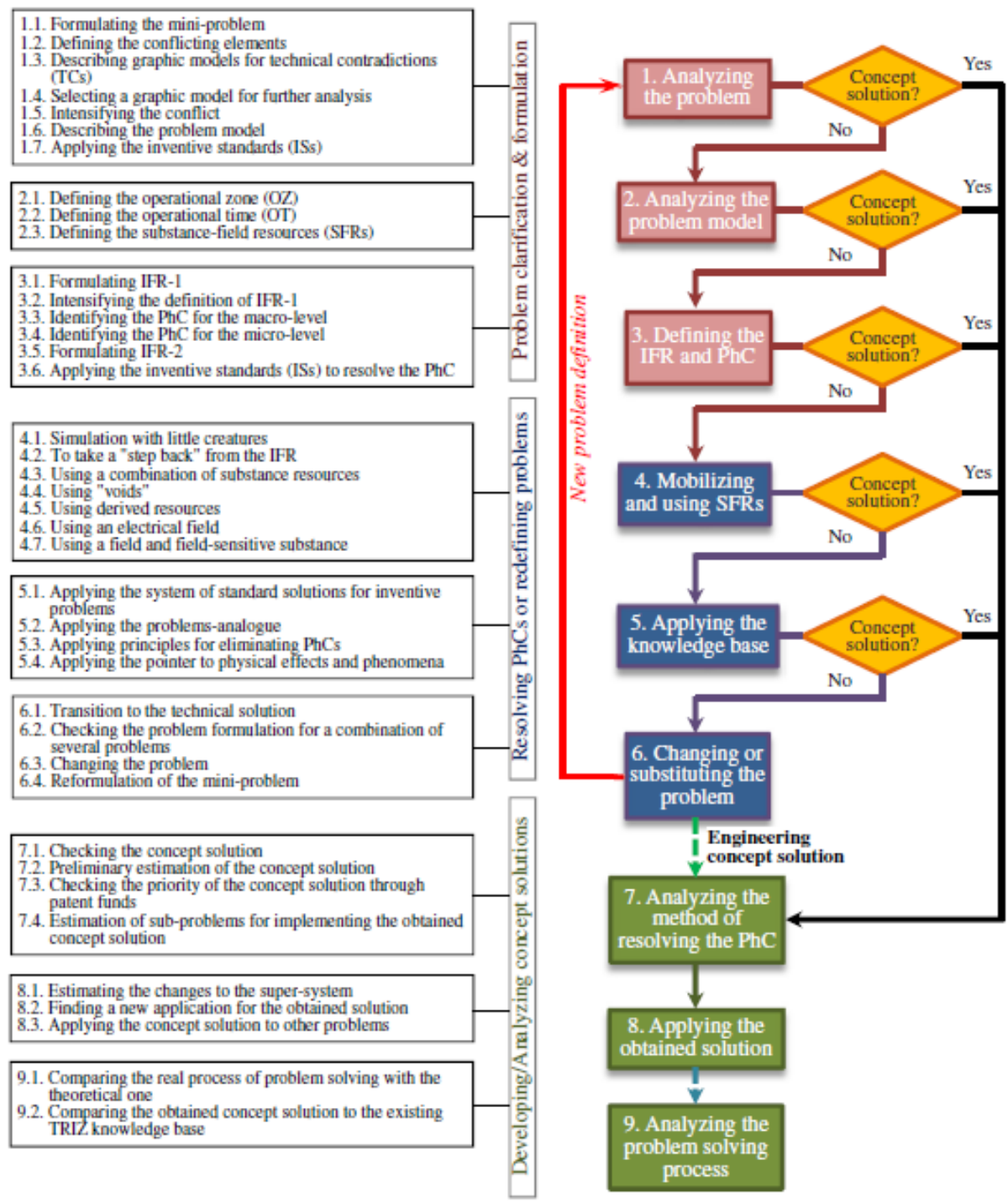

Figure 6: Framework of ARIZ 85C (Chou 2014)

\subsubsection{Problem-solving team}

The problem was inspired by a real operations management situation (see description above) that was altered to be analyzed within the context of a scaled-down problem-solving team. The team consisted of the following:

- Two volunteers who were in charge of managing the problem-solving process by applying ARIZ 85A-a meta-method for analyzing the initial problem and stating the contradiction (reformulated problem) to be addressed - and ARIZ 85C to overcome the stated contradiction. Both volunteers had received a 20-hour introduction to TRIZ methodology several years ago and had a general background in industrial engineering. Note that the company's Kanban system was not an "academic Kanban." As resources for preparing their work, they received the initial problem statement and the guidelines for the ARIZ 85 A and ARIZ 85C methodologies. As additional resources, they were provided a discrete event simulation system (Witness) for simulating the performances of the existing and future systems.

- A TRIZ methodology expert who taught the material and applied it to the product design framework. He did not have an active background in SCM or operations management. His job was to provide methodological support to the two problem solvers (volunteers). His role was not limited to providing support for the use of meta-methods; he eventually also provided the problem solvers with adequate lower-level TRIZ methods when necessary. 
- One of the authors, who played the role of the "owner" of the problem. His role was to provide the other members of the team with information about the constraints, environment and other specific elements of the problem and available resources. He was only supposed to provide this information when he was asked by the problem-solving team. He also had to validate, reject or judge proposals for solutions based on his knowledge of the company-specific environment.

\subsubsection{Results of the first experiment}

Before discussing questions 1 and 2 stated in section 2.3, general feedback about this experiment includes the following:

- The ARIZ 85A framework and its associated sub-methods for analyzing the initial situation provided guidance for analyzing the existing system and led to reorganization of the initial problem into several subproblems. This exercise was a good guide for learning the limits of the process from the owner of the problem. Several systems of contradictions that provided different orientations for a solution search were provided. One system was chosen and treated by the solving method ARIZ 85C.

- The use of the solving method ARIZ 85C provided and clearly invented solutions based on principles similar to the existing one (the working principle of these solutions was reinvented through the method). Nevertheless, when modifying the objectives by making them increasingly challenging and considering the evolution of the system environment, it was also possible to propose solutions. When considering specific elements of the situation, it was occasionally possible to propose solutions that were different from standard existing solutions.

- The Pareto front of the solution outperforms the Pareto front from the initial system.

- Finally, concerning the obtained solutions, it was possible to reverse engineer the use of the TRIZ matrix by crossing 39 basic technical parameters and linking them to several of the 40 inventive principles for solving technical contradictions. The process was not straightforward. Indeed, it was not easy for the volunteers to map the technical parameters of our problem to those proposed in the TRIZ matrix. This experience allowed us to understand why papers proposed to customize or rebuild this type of matrix or later the inventive standard in the eco-design context.

\subsubsection{Discussion of the first experiment}

Concerning the area of GSC in which the TRIZ could be helpful or at least useful, the previous experiment confirms the results of previous studies in which some TRIZ methods were successfully used to address GSCM problems in the area of operations management systems rather than only for the green design of product or packaging. Moreover, the experiment provides examples of when ARIZ 85A and ARIZ 85C can be used directly, with minor changes, to address these problems. Note that the minor change here was the removal of the use of the inventive standards; we did not test whether the inventive standards could also be used.

Thus, for some SCM problems, it seems unnecessary, from a functional point of view, to change the TRIZ grounding models or the more recent classical TRIZ tools. Nevertheless, during the analysis of the initial situation, the methodology used (meta-method ARIZ 85A) pushes the user to answer questions about the system. He could be helped at some steps by certain TRIZ tools, but, from the authors' points of view, some could be replaced by well-known tools used in industrial management (Zhang et al. 2014) or by the methods proposed in the paper analyzed in section 2.3.2 (Russo \& Serafini 2015; Russo et al. 2011; Russo et al. 2014). The organization of these standard methods within the framework of the initial situation analysis and the problem statement could provide a methodology based on method with which the user of SC is more familiar; an example of this type of approach can be found in the infrastructure planning area (Mirakyan \& De Guio 2014). Nevertheless, there are useful analysis methods, such as the so-called "multi-screen" description, that are specific to the TRIZ.

Concerning the solving phase, we did not encounter major difficulties when using ARIZ 85C. We used the standard tools without specific customizations, which led us to make a comment concerning the use of the matrix and of specific tools. The difficulty we had in reverse engineering the use of the matrix let us understand how it would be difficult to use it within inventive problem solving. First, we think that we would not be able to recognize the conflicting parameters in the matrix without knowing the solution; but in inventive problem solving, the solution is not known beforehand. Second, the inventive principle would not have provided us the information about the place in the system in which the principle should be applied. This problem is not encountered when using ARIZ 85C. 
When testing the methodology with different constraints, different evolutions of the environment and with more challenging goals, different solutions were found, and the methodology could be applied. Solutions could be obtained as in an inventive process, which encourages the authors to address more real and challenging problems in the future by using the more mature existing TRIZ methods.

\subsection{Second experiment}

\subsubsection{Description of the second experiment}

The second experimental situation addressed the same problem as in the first experiment, but the solving process was different. This experiment was intended to compare an automatic computerized approach based on a simulation developed in (Lin et al. 2013) and (Lin et al. 2015) as an alternative to the use of ARIZ 85A for obtaining a system of contradictions, which is the starting point for ARIZ 85C. The first point is that the method might enhance dramatically the delay of the initial analysis, at least in some complex situations. The second point will be developed in the third experiment, below.

The process for obtaining the contradiction can be summarized as follows (the reader can obtain more-detailed information about the methodology in (Lin 2016). First, a model of the existing system is implemented on a discrete event simulator (Witness), and a set of experiments is performed to provide a sample of the mapping between the action parameters and the performance parameters (stock breakdown and stock value). The Witness experimenter allows performing mono-objective optimization (i.e., the sequence of action parameters can be managed due to a simulated annealing program). Thus, this software function is used to find the best values for each evaluation parameter. Because no action parameter configuration of the existing system was able to obtain simultaneously the best performance value for the evaluation parameters, an ideal (fictive) point defined by the best value of each performance parameter of the existing system was defined as the desired result for the system of contradictions to be determined. Then, technical contradictions were defined with the search algorithm and method (cf. Figure 7) described in (Lin et al. 2013) and the generalized physical contradictions associated with the technical contradictions were sought with the algorithm and method described in (Lin et al. 2015). The obtained contradictions are then compared with those obtained in the previous experiment with ARIZ 85A.

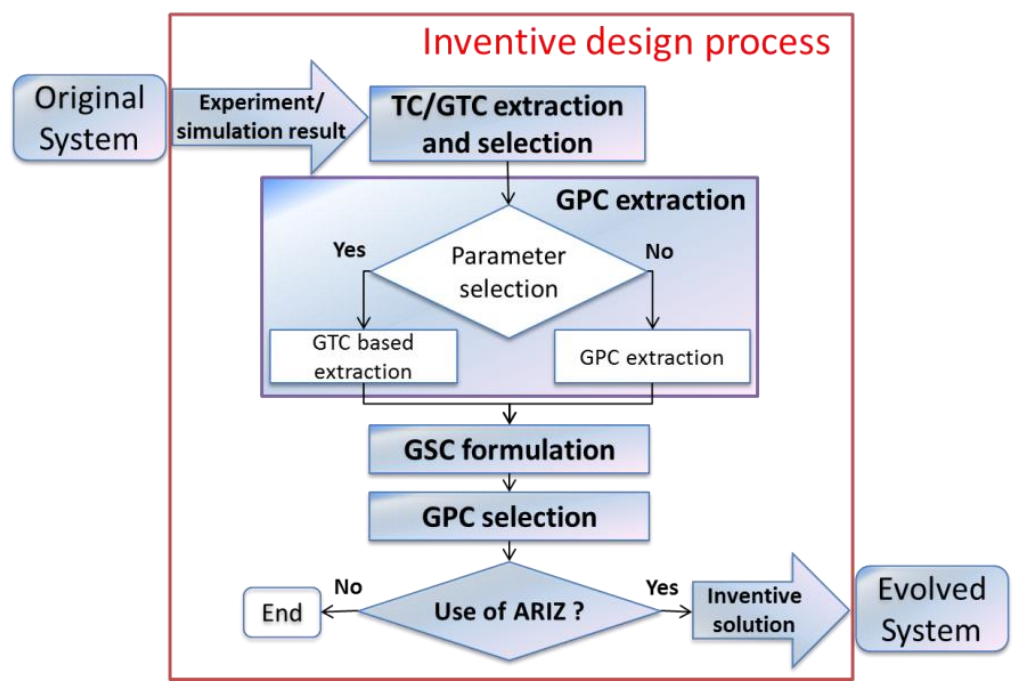

Figure 7: Method of inventive design problem solving

\subsubsection{Results and discussion of the second experiment}

When comparing the results of the analysis of the initial situation as described above on the one hand, and by ARIZ 85A on the other hand, it appears that the computer was able to provide relevant systems of contradictions to start the solving process in a shorter period of time. However, the analysis of the initial situation (ARIZ 85A) provided more systems of contradictions, representing more facets of the problem that could lead to additional solutions. Indeed, the simulator can only express problems by using the parameters embedded in its model. Moreover, with the computer extraction approach, the obtained system of contradiction had to be validated or understood by the problem solver (the problem statement can appear to be a cognitive gap). However, using the initial situation methodology analysis means that the problem solver enters the problem more slowly; the method acts as a progressive learning process for the limits of the system. 
Note also that the computer analysis approach did precise some systems of contradiction also obtained with ARIZ 85A; the computer approach did highlight that the physical contradiction linked to the technical contradiction only holds for a given combination of the action parameters that are not involved in the classical system of contradictions obtained with ARIZ85A. This information provides insight to the understanding of the inventive problem. From the point of view of the TRIZ as theory, the system contradiction that was highlighted with the second experimental approach is not a classical TRIZ contradiction; rather, it is a generalized system of contradictions. However, by chance, the classical TRIZ system of contradictions obtained with ARIZ 85A is established for a restricted combination of the action parameters. This type of generalized system of contradictions remains an entry point for the ARIZ 85C solving method used in the first experiment.

The conclusion we derive from this experiment is that both ARIZ 85A and the data-oriented approach are useful for addressing GSC inventive problems. Moreover, some specific generalized contradictions can be addressed with ARIZ 85C without change.

\subsection{Third experiment}

\subsubsection{Motivations}

In the literature of engineering design, some limitations of the TRIZ and of the TRIZ model of contradictions have been highlighted. As mentioned previously, a generalized model of contradiction has been proposed to bypass this theoretical limitation. The purpose of this experiment is to ascertain whether this limitation is also established in GSC problems and draw conclusions about the question stated previously.

\subsubsection{Description of the system and inventive problem}

This case involves a simple manufacturing system managed by Kanban cards simulated with the aid of the flow simulation software Witness 14 . The system is composed of one manufacturing machine producing two different items stored in two independent inventories, stock_1 and stock_2, and delivered to customers. The interval time of customers' arrival time follows a uniform random distribution, i.e., the interval of customers' arrival time at inventory_1 follows a uniform distribution $(0.18,0.22)$, and the interval of customers' arrival time at stock_2 follows a uniform distribution $(0.9 ; 1.1)$. It is a simple pull system, in which Kanban cards are sent back to the manufacturing machine when the container is empty. The Kanban card provides the quantity to be placed in a container. The manufacturing machine has a different set up time for each item (i.e., 1 time unit for the first item and 2 time units for the second item); the operation time is 0.1 time unit for each item. The transportation Kanban Size from the machine to the customers' inventories is one Kanban. The scheduling rule for the machine gives priority to the items of inventory_2; i.e., Kanban cards arriving from inventory_2 are placed at the beginning of the manufacturing machine waiting list, whereas the arriving Kanban cards from inventory_1 are placed at the end of the waiting list. Thus, a setup is performed any time the type of item (Kanban) changes in the Kanban waiting line. The total running time of one simulation is 1000 time units (1 time unit corresponds to 1 hour), with 10 time units required for warm-up time. During the warm-up time, all of the Kanban cards come into the model and go to the manufacturing machine; thus, the initial stock of two inventories is from the "manufacturing warm-up time".

This study is modeled as follows: the Kanban size (quantity of items corresponding to one Kanban card) and the number of Kanban cards are the action parameters of the system on which we can act. To evaluate the performance of this system, the average stock in the inventories, the average waiting time for customers and a "green" transportation cost proportional to the number of Kanban traveling from supplying machine to the inventories are defined as the evaluation parameters for both items. In summary, four action parameters are defined: number of Kanban for item 1 (NK1), number of Kanban for item 2 (NK2), Kanban size for item 1 (KS1), and Kanban size for item 2 (KS2). In addition, the six evaluation parameters are average stock in stock 1 (AS1), average stock in stock 2 (AS2), service breakdown for item 1 (SB1) corresponding to the average lateness of the delivery to customer 1, service breakdown for item 2 (SB2), transportation cost for item_1 (TR1) and transportation cost for item_2 (TR2). The definition of the range of action parameters for optimization should first be defined by an engineer; then, it should be deduced whether there is a good solution out of the defined range through a statistical analysis of generated solutions. For our case, the range is defined as 1 to 10 for each action parameter.

Once the action parameters (NK1, NK2, KS1, and KS2) and evaluation parameters (AS1, SB1, AS2, SB2, TR1, and TR2) are determined, the experiments are performed. The Witness provides tools for random experiments. We used a random experiment as an optimization, and 1039 experiments were performed. The best values obtained separately by optimization means for each evaluation parameter of this system was SB1 $=0$, AS $1=0$, $\mathrm{SB} 2=0, \mathrm{AS} 2=0, \mathrm{TR} 1=225$ and $\mathrm{TR} 2=101$. No experiments provided a solution in which all of the evaluation 
parameters were simultaneously within the interval [0; 0.1] for AS1, SB1, AS2, and SB2 in [225,250] and [101,120] for TR1 and TR2, respectively. This desired solution space could not be reached by the abovedescribed system; thus, we decided to choose it as the desired solution space of the inventive problem.

Based on the previous experiment, a full factorial experiment was conducted. The numbers of levels for KS1, KS2, NK1 and NK2 are 5, 6, 4 and 5, respectively. The system of contradiction was performed, and the contradictions were defined with the same algorithm as in the second experiment; however, as we will see in the next section, ARIZ 85C could not be applied directly to the obtained contradiction.

\subsubsection{Results and discussion of the third experiment}

The previous process identified 66 Generalized Technical Contradictions (GTC), including 6 classical TRIZ Technical Contradictions. Only one GTC involves the six evaluation parameters; when the objectives of AS1 AS2 and TR1 are reached, the objectives for SB1, SB2 and TR2 are not reached. No classical TRIZ contradiction or GTC for the 6 TC or for the GTC involving the 6 evaluation parameters is obtained (i.e., the conflict at the level of the action parameters cannot be described by the change in value of only one parameter of the model). The Generalized Physical contradiction associated with any of the previous GTC consists of at least 3 action parameters. Thus, for the GTC involving the 6 evaluation parameters, and given KS1 in the range [8, $10]$, concept 1 of the GPC is $(\mathrm{KS} 2=10),(\mathrm{NK} 1=7)$ and $(\mathrm{NK} 2=3)$, and concept 2 is $(\mathrm{KS} 2=2)$, $(\mathrm{NK} 1=1)$ and $(\mathrm{NK} 2=1)$.

Note that the algorithms used for the contradictions search result in an exhaustive search and deduce the consequences of the previous result for the questions posed at the beginning of the paper. The obtained system of contradictions cannot be obtained with ARIZ 85A. Indeed, the $6 \mathrm{TC}$ could be found eventually, but because no classical TRIZ physical contradiction is associated with them for this system, no classical TRIZ system of contradiction can be found and, unfortunately, neither ARIZ 85A, nor any classical TRIZ tools informs the user when no TRIZ contradiction is present in the inventive problem. Thus, no input for ARIZ 85C can be provided because ARIZ 85C is not designed for addressing any general system of contradictions. It was possible to address the general system of contradictions of the problem in experiments 1 and 2, but not in the case of experiment 3. The number of inventive problems in GSC similar to the one in experiment 3 is increasing. Therefore, there are inventive problems in the GSC domain that require new tools for addressing their underlying contradictions. There is room for progress at the methodological level of the TRIZ for considering the complex system of contradictions behind some inventive problems in GSC. Moreover, search algorithms used for this experiment can only address 12 evaluation parameters and 13 action parameter problems when there is no classical TRIZ technical or physical contradiction in the problem. However, the GSC systems can involve more parameters; thus, to use this approach, new search algorithms for the generalized contradiction must be developed.

The limitation of the use of the TRIZ highlighted in this example is not yet mentioned in the GSC literature. The limitation of the TRIZ model of contradictions was mentioned in the engineering design area for product design, which led to the development of the model of generalized contradiction. This example shows that the limitation of the classical TRIZ model of contradiction is also established for GSC operations management problems. When TRIZ practitioners are asked why they do not use ARIZ, they often answer that it is difficult to find the system of contradictions, but very few know that one of the underlying reasons for this difficulty is that the classic TRIZ model of contradiction they are seeking might not hold for their model of system. A direction of improvement could be to provide them a means to let them quickly know whether a classical TRIZ system of contradiction holds; then, they could know when they could use ARIZ. Note also that (Lin et al. 2013) showed that in theory, when addressing more than two objectives, the inventive problem might not be describable with classical TRIZ technical contradictions. This point implies that TRIZ methods focusing only on technical contradictions also cannot be used in this case; in this circumstance, customization of the matrix will not change the situation. The author hypothesizes several reasons why these limitations are not mentioned in the GSC literature:

People who tried to use TRIZ for such problems failed and did not report it,

- The models of inventive problems that were addressed to date with TRIZ in GSC are not yet sufficiently complex but might become so in the future. Indeed, the empirical study in (Lin et al. 2013) showed that in a multi-objective problem, the more objectives are reached, the lower the probability to model the inventive problem with classical TRIZ contradictions. Thus, in the future, when the system is improved, the number of inventive problems that cannot be described with the classical TRIZ model of contradictions will increase.

This finding also explains why some papers highlight as a weakness of the TRIZ the process of stating the contradiction (Kubota \& da Rosa 2013). The major consequence of this limitation is that all of the methods 
intended to improve the lack of the TRIZ for stating the problem and the contradiction before using the TRIZ solving part should be adapted to make the user aware of whether the TRIZ model of contradictions holds in his situation because in the future, more situations in which the TRIZ model of contradictions does not hold will appear. When no classical TRIZ contradiction can be established, these new methods should be improved to provide generalized contradictions.

\section{Conclusion and research challenges}

The purpose of this paper was to review the practice of using the TRIZ in GSC and to identify new research challenges. First, the unique contributions of the paper are discussed; then, research challenges and future research directions are proposed.

\subsection{Unique contributions}

Based on the authors' background in TRIZ information and in GSC fields, the literature was analyzed to answer the question, "To what extent is it necessary to evolve TRIZ tools, methods and theoretical grounding to address GSC inventive problems?" The analysis of the GSC literature shows that the TRIZ was primarily applied for product design applications, the domain in which TRIZ was designed. Few trials were performed in the other areas of GSC in which there are also established inventive problems to be solved. For these other areas, the reviewed papers primarily proposed the use of the TRIZ method based on the use of the TRIZ matrix for technical contradictions. Moreover, they proposed customizations to fit it into the SCM domain. Surprisingly, only one paper proposes the use of ARIZ 85C, which is the most mature meta-method of the TRIZ without modification. Additionally, some limitations of the TRIZ that are mentioned in the engineering design area were not mentioned or encountered in the analyzed literature.

To explore the extent to which the more mature meta-methods of classical TRIZ, namely ARIZ 85 A, C and the related sub-methods, can be used as in GSM problems, three experiments addressing GSC problems were conducted. The examples were also chosen to explore types of GSC problems that were not yet addressed with TRIZ. In the same case as in experiment 1 , ARIZ $85 \mathrm{~A}$ can be used as is for stating the contradiction and understanding the problem; ARIZ 85C can be used to address the contradictions stated with ARIZ 85A. This experience allowed us to understand why papers proposed to customize or rebuild the TRIZ matrix or later the inventive standard in the eco-design context; this is because it is not easy to map the technical parameters of the problems to those proposed in the TRIZ matrix. Experiment 2 shows that when simulation models of the existing GSC system are available, the identification of the contradictions can be replaced by computer search methods, as proposed by Lin et al. (Lin et al. 2013) and (Lin et al. 2015). The second experiment illustrates the link between simulation, optimization and invention, which can contribute to automatize contradictions' extraction and to proposed relevant inventive solutions. This can be used and applied in many cases, particularly in green supply chain design of products as well as process. Experiment 3 shows an example in which no classical TRIZ contradiction existed. This finding also explains why some papers highlight the process of stating the contradiction as a weakness of the TRIZ. It highlights the limitations of the use of ARIZ 85A and ARIZ 85C when the conflict to overcome contains more than two evaluation parameters and one action parameter. When no classical TRIZ contradictions can be established, the authors propose to use a model based on a generalized system of contradictions that enables a stating of the contradiction and a starting of the TRIZ solving process.

\subsection{Research challenges and future directions}

Although many recent articles tackling multi-objective optimization for trade-offs and innovation for green design exist, none has mentioned combining design and optimization for innovation in the supply chain. While these issues were raised, the need for clarifying this link still remains. The automatization of the problem-solving loop based on simulation-optimization-invention is a possible future research direction. Some papers offer innovations in special cases, but none offers a global view/framework or even a roadmap for green or sustainable innovation that can be studied and completed by TRIZ mature methods or tools such as ARIZ.

Most of the previous studies developed optimization models based on the maximization of eco-efficiency and sought to maximize economic benefits while having minimal environmental impact on the supply chain network (Zhao et al. 2016). Quantitative optimization methods are focused on system analysis for understanding and evaluation of different scenarios or strategies to choose the best solutions (optimization) and do not indicate the limits of the proposed solutions. As far as the optimization methods are concerned, the limitations of the best solutions are situated on Pareto front. No paper worked on innovation beyond the optimized trade-offs. The simulation-optimization-invention loop would enable the alteration of recent models and to go beyond the Pareto of proposed trade-offs. Qualitative methods indicated only the influence and neither the sense of influence nor 
the compatibility of partial solutions. Regarding these studies and referring to future research propositions (Govindan and Soleimani 2016), the opportunity for future research is in the analysis of decision and evaluation variables (parameters) and their relationships, which should be developed more extensively in the context of decision problem space and evaluation solution space.

The study was focused on the green supply chain to solve contradictions between environmental impacts and economic benefits. Future research may extend the search scope to more general sustainable supply chain problems (Franceschini et al. 2015), taking into account the social aspect; this would raise the importance of multi-objective problems and the necessity of using the generalized system of contradictions within the TRIZ theory. Consequently, the following challenges for the use of TRIZ in GSC inventive problems are identified:

- Providing methods for quickly establishing the existence of classical TRIZ contradictions even when tens of parameters describe the model of the existing systems or for informing the problem solver when no TRIZ contradictions are present in a given inventive problem in GSC. Such methods would permit the determination of whether ARIZ 85C could be used and avoid a long and fruitless search for a system of contradictions.

- Finding alternatives to the algorithms proposed in (Lin et al. 2013) and (Lin et al. 2015) to be able to establish the generalized contradictions of inventive problems described, with tens of evaluation parameters and hundreds of action parameters. This determination could be made in two directions or steps: first, by focusing on the specific case of the generalized contradictions that can be treated with ARIZ 85C without change (as in example 2); second, addressing the general case. The knowledge of the more general system of contradictions is useful, although the system of contradiction could not be addressed by ARIZ because it provided a deeper understanding of what the problem was and which design parameters were involved in the problem and those which were not.

- Evolving ARIZ 85C or substitute it with methods that could address the inventive problems that ARIZ $85 \mathrm{C}$ cannot treat.

These issues are even more important given the reality that an increasing number of inventive problems within the GSC domain cannot be treated with the TRIZ. 


\section{References:}

Abramov, O. et al., 2015. TRIZ-based approach for accelerating innovation in chemical engineering. Chemical Engineering Research and Design, 3, pp.1-7.

Altshuller, G.S., 1985. Analysis of the initial situation. Available at: http://www.seecore.org/d/ais85a_en.pdf [Accessed March 11, 2016].

Altshuller, G.S., 1984. Creativity As an Exact Science, CRC Press.

Altshuller, G.S., 1999. The Innovation Algorithm: TRIZ, Systematic Innovation and Technical Creativity, Technical Innovation Center, Inc.

Anoop, A.T. \& Regi Kumar, V., 2013. A review of green supply chain management issues in indian bottled water industry. International Journal of Innovative Research in Science, Engineering and Technology, 2(1), pp.395-406.

Ardente, F., Beccali, G. \& Cellura, M., 2003. Eco-sustainable energy and environmental strategies in design for recycling: the software "ENDLESS." Ecological Modelling, 163, pp.101-118.

Ariffin, R. et al., 2015. Design for environment and design for disassembly practices in Malaysia: a practitioner's perspectives. Journal of East-West Business, 108, pp.331-342.

Babazadeh, R. et al., 2015. An integrated data envelopment analysis-mathematical programming approach to strategic biodiesel supply chain network design problem. Journal of Cleaner Production.

Bashkite, V. \& Karaulova, T., 2012. Integration of green thinking into lean fundamentals by theory of inventive problems-solving tools. In 23rd International DAAAM Symposium. pp. 345-350.

Büyüközkan, G. \& Berkol, Ç., 2011. Designing a sustainable supply chain using an integrated analytic network process and goal programming approach in quality function deployment. Expert Systems with Applications, 38(11), pp.13731-13748.

Chen, J.L. \& Chen, W., 2007. TRIZ Based Eco-Innovation in Design for Active Disassembly. conference on Life Cycle Engineering, pp.83-87.

Chou, J.-R., 2014. An ARIZ-based life cycle engineering model for eco-design. Journal of Cleaner Production, 66, pp.210-223.

Chulvi, V. \& Vidal, R., 2011. Usefulness of evolution lines in eco-design. Procedia Engineering, 9, pp.135-144.

Coronado, M., Segadães, A.M. \& Andrés, A., 2015. Using mixture design of experiments to assess the environmental impact of clay-based structural ceramics containing foundry wastes. Journal of Hazardous Materials, 299, pp.529-539.

D’Anna, W. \& Cascini, G., 2011. Supporting sustainable innovation through TRIZ system thinking. Procedia Engineering, 9, pp.145-156.

Diabat, A., Kannan, D. \& Mathiyazhagan, K., 2014. Analysis of enablers for implementation of sustainable supply chain management - A textile case. Journal of Cleaner Production, 83(2014), pp.391-403.

Diabat, A., Khodaverdi, R. \& Olfat, L., 2013. An exploration of green supply chain practices and performances in an automotive industry. The International Journal of Advanced Manufacturing Technology, 68(1-4), pp.949-961.

Dubois, S., Eltzer, T. \& De Guio, R., 2009. A dialectical based model coherent with inventive and optimization problems. Computers in Industry, 60(8), pp.575-583.

Dubois, S., De Guio, R. \& Rasovska, I., 2011. Different ways to identify generalized system of contradictions, a strategic meaning. Procedia Engineering, 9, pp.119-125.

Dubois, S., Rasovska, I. \& De Guio, R., 2009. Interpretation of a General Model for Inventive Problems , the Generalized System of Contradictions. In Proceedings of the 19th CIRP Design Conference-Competitive Design. 
Esfahbodi, A. et al., 2016. Governance pressures and performance outcomes of sustainable supply chain management - An empirical analysis of UK manufacturing industry. Journal of Cleaner Production, pp.113.

Foster, S.T., Wallin, C. \& Ogden, J., 2011. Towards a better understanding of supply chain quality management practices. International Journal of Production Research, 49(8), pp.2285-2300.

Franceschini, S., Faria, L.G.D. \& Jurowetzki, R., 2015. Unveiling scientific communities about sustainability and innovation. A bibliometric journey around sustainable terms. Journal of Cleaner Production, 127, pp.72-83.

Fresner, J. et al., 2010. The theory of inventive problem solving (TRIZ) as option generation tool within cleaner production projects. Journal of Cleaner Production, 18(2), pp.128-136.

Garg, D., Luthra, S. \& Haleem, A., 2014. Ranking of Performance Measures of GSCM towards Sustainability : Using Analytic Hierarchy Process. International Journal of Social, Behavioral, Educational, Economic and Management Engineering, 8(3), pp.743-749.

Govindan, K., 2015. Embedding Sustainability Dynamics in Supply Chain Relationship Management and Governance Structures: Introduction, Review and oppurtunities. Journal of Cleaner Production, (2016).

Govindan, K., Khodaverdi, R. \& Jafarian, A., 2013. A fuzzy multi criteria approach for measuring sustainability performance of a supplier based on triple bottom line approach. Journal of Cleaner Production, 47(2013), pp.345-354..

Govindan, K. \& Soleimani, H., 2016. A review of Reverse Logistics and Closed-Loop Supply Chains: A Journal of Cleaner Production Focus. Journal of Cleaner Production.

Huang, Y. et al., 2016. Green supply chain coordination with greenhouse gases emissions management: a gametheoretic approach. Journal of Cleaner Production, 112, pp.2004-2014.

Hugo, A. \& Pistikopoulos, E.N., 2005. Environmentally conscious long-range planning and design of supply chain networks. Journal of Cleaner Production, 13(15), pp.1471-1491.

Ilevbare, I.M., Probert, D. \& Phaal, R., 2013. A review of TRIZ, and its benefits and challenges in practice. Technovation, 33(2-3), pp.30-37.

Jamshidi, R., Fatemi Ghomi, S.M.T. \& Karimi, B., 2012. Multi-objective green supply chain optimization with a new hybrid memetic algorithm using the Taguchi method. Scientia Iranica, 19(6), pp.1876-1886.

Kannan, D., Govindan, K. \& Rajendran, S., 2015. Fuzzy Axiomatic Design approach based green supplier selection: a case study from Singapore. Journal of Cleaner Production, 96(Integrating Cleaner Production into Sustainability Strategies), pp.194-208.

Khomenko, N. \& De Guio, R., 2007. OTSM Network of Problems for representing and analysing problem situations with computer support. In Trends in Computer Aided Innovation.2nd IFIP Working Conference on Computer Aided Innovation, Technical Center Brighton, Springer, USA (2007). pp. 77-88.

Khomenko, N., Guio, R. De \& Cavallucci, D., 2009. Enhancing ECN's abilities to address inventive strategies using OTSM-TRIZ. International Journal of Collaborative Engineering, 1, pp.98-113.

Kim, K. et al., 2006. Supply planning model for remanufacturing system in reverse logistics environment. Computers \& Industrial Engineering, 51(2), pp.279-287.

Kubota, F.I. \& da Rosa, L.C., 2013. Identification and conception of cleaner production opportunities with the Theory of Inventive Problem Solving. Journal of Cleaner Production, 47, pp.199-210.

Laari, S. et al., 2016. Firm performance and customer-driven green supply chain management. Journal of Cleaner Production, 112(2016), pp.1960-1970.

Lin, L. et al., 2013. Algorithm for identifying generalised technical contradictions in experiments. Journal Européen des Systèmes Automatisés, 47(4-8), pp.563-588.

Lin, L. et al., 2015. An exact algorithm to extract the generalized physical contradiction. International Journal on Interactive Design and Manufacturing (IJIDeM), 9(3), pp.185-191. 
Lin, L., 2016. Optimization methods for inventive design. PhD dissertation University of Strasbourg.

Liu, C. \& Chen, J.L., 2001. Development of product green innovation design method. In Proceedings Second International Symposium on Environmentally Conscious Design and Inverse Manufacturing. IEEE Comput. Soc, pp. 168-173.

Luthra, S. et al., 2016. An integrated framework for sustainable supplier selection and evaluation in supply chains. Journal of Cleaner Production.

Masanet, E. \& Horvath, A., 2007. Assessing the benefits of design for recycling for plastics in electronics: A case study of computer enclosures. Materials \& Design, 28, pp.1801-1811.

Masui, K. et al., 2003. Applying Quality Function Deployment to environmentally conscious design. International Journal of Quality \& Reliability Management, 20(1), pp.90-106.

Mirakyan, A. \& De Guio, R., 2014. A methodology in innovative support of the integrated energy planning preparation and orientation phase. Energy, 78, pp.916-927.

Mirkouei, A. et al., 2016. Reducing the cost and environmental impact of integrated fixed and mobile bio-oil refinery supply chains. Journal of Cleaner Production, 113(2016), pp.495-507.

Morose, G., Shina, S. \& Farrell, R., 2011. Supply chain collaboration to achieve toxics use reduction. Journal of Cleaner Production, 19(5), pp.397-407.

OECD, 2009. Eco-innovation in industry enabling green growth., Paris: OECD publishing.

OECD, 2005. Oslo Manual: The Measurement of Scientific and Technological Activities, Paris: OECD Publishing.

Pishvaee, M.S. \& Razmi, J., 2012. Environmental supply chain network design using multi-objective fuzzy mathematical programming. Applied Mathematical Modelling, 36(8), pp.3433-3446.

Rajesh, R. \& Ravi, V., 2015. Supplier selection in resilient supply chains: A grey relational analysis approach. Journal of Cleaner Production, 86(2015), pp.343-359.

Rau, H. \& Fang, Y., 2009. Conflict resolution of product package design for logistics using the TRIZ method. In Proceedings of the Eighth International Conference on Machine Learning and Cybernetics. pp. 28912896.

Rezapour, S. et al., 2015. Competitive closed-loop supply chain network design with price-dependent demands. Journal of Cleaner Production, 93, pp.251-272.

Russo, D., Regazzoni, D. \& Montecchi, T., 2011. Eco-design with TRIZ laws of evolution. Procedia Engineering, 9, pp.311-322.

Russo, D., Rizzi, C. \& Montelisciani, G., 2014. Inventive guidelines for a TRIZ-based eco-design matrix. Journal of Cleaner Production, 76, pp.95-105.

Russo, D. \& Serafini, M., 2015. Anticipating the Identification of Contradictions in Eco-design Problems. Procedia Engineering, 131, pp.1011-1020.

Seman, N.A.A. et al., 2012. The Relationship of Green Supply Chain Management and Green Innovation Concept. Procedia - Social and Behavioral Sciences, 57(null), pp.453-457.

Siu, J., Lam, L. \& Lai, K.-H., 2015. Developing environmental sustainability by ANP-QFD approach: the case of shipping operations. Journal of Cleaner Production, 105, pp.275-284.

Soh, S.L., Ong, S.K. \& Nee, A.Y.C., 2015. Application of Design for Disassembly from Remanufacturing Perspective. Procedia CIRP, 26, pp.577-582.

Sokol, A. et al., 2008. The development of inventive thinking skills in the upper secondary language classroom. Thinking Skills and Creativity, 3(1), pp.34-46.

Srinivasan, R. \& Kraslawski, A., 2006. Application of the TRIZ creativity enhancement approach to design of inherently safer chemical processes. Chemical Engineering and Processing: Process Intensification, 45(6), 
pp.507-514.

Srivastava, S.K., 2007. Green supply-chain management: A state-of-the-art literature review. International Journal of Management Reviews, 9(1), pp.53-80.

Strasser, C. \& Wimmer, W., 2003. Eco-innovation, combining eco-design and TRIZ for environmentally sound product development. DS 31: Proceedings of ICED 03, the 14th International Conference on Engineering Design, Stockholm, pp.383-384.

Su, C.-M. et al., 2015. Improving sustainable supply chain management using a novel hierarchical greyDEMATEL approach. Journal of Cleaner Production, 134(2016), pp.469-481.

Talaei, M. et al., 2016. A robust fuzzy optimization model for carbon-efficient closed-loop supply chain network design problem: A numerical illustration in electronics industry. Journal of Cleaner Production, 113(2016), pp.662-673.

Thurnes, C.M., Zeihsel, F. \& Hallfell, F., 2014. TRIZ for waste-elimination in a " Lean Production" Environment. triz-journal, pp.1-8. Available at: https://triz-journal.com/triz-for-waste-elimination-in-alean-production-environment/.

Vidal, R. et al., 2015. Fuzzy Cognitive Map-based selection of TRIZ (Theory of Inventive Problem Solving) trends for eco-innovation of ceramic industry products. Journal of Cleaner Production, 107, pp.202-214.

Wan, Y.K. et al., 2015. Fuzzy multi-footprint optimisation (FMFO) for synthesis of a sustainable value chain: Malaysian sago industry. Journal of Cleaner Production, 128(2016), pp.62-76.

Wu, Y.-H. \& Ho, C.C., 2015. Integration of green quality function deployment and fuzzy theory: a case study on green mobile phone design. Journal of Cleaner Production, 108, pp.271-280.

Yang, C.J. \& Chen, J.L., 2011. Accelerating preliminary eco-innovation design for products that integrates casebased reasoning and TRIZ method. Journal of Cleaner Production, 19(9-10), pp.998-1006.

Yang, C.J. \& Chen, J.L., 2012. Forecasting the design of eco-products by integrating TRIZ evolution patterns with CBR and Simple LCA methods. Expert Systems with Applications, 39(3), pp.2884-2892.

Yi, P. et al., 2016. A retailer oriented closed-loop supply chain network design for end of life construction machinery remanufacturing. Journal of Cleaner Production, 124, pp.191-203.

Zhang, F., Yang, M. \& Liu, W., 2014. Using integrated quality function deployment and theory of innovation problem solving approach for ergonomic product design. Computers and Industrial Engineering, 76(1), pp.60-74.

Zhao, R. et al., 2016. An Optimization Model for Green Supply Chain Management by Using a Big Data Analytic Approach. Journal of Cleaner Production.

Zhou, Y. \& Zhao, L., 2016. Impact analysis of the implementation of cleaner production for achieving the lowcarbon transition for SMEs in the Inner Mongolian coal industry. Journal of Cleaner Production.

Zhu, Q., Sarkis, J. \& Lai, K., 2008a. Confirmation of a measurement model for green supply chain management practices implementation. International Journal of Production Economics, 111(2), pp.261-273.

Zhu, Q., Sarkis, J. \& Lai, K., 2008b. Green supply chain management implications for "closing the loop." Transportation Research Part E: Logistics and Transportation Review, 44(1), pp.1-18. 